sterilem Verbandstoff), bis derselbe nur noch etwa Bluttemperatur hat, was man durch Anlegen ans geschlossene Auge feststellen kann, und setzt die Flasche so auf die Brustwarze, daB die Warze in die Oeffnung des Halses hineingepaßt und der Rand dem Warzenhof anliegt. Nach einer Minute kühlt sich die Flasche ab, es entsteht, wie beim Schröpfkopf, ein luftverdünnter Raum, in welchen die Milch in mehreren Strahlen hineinstürzt, um in kurzer Zeit, etwa 8-10 Minuten, z. B. bei einer Wöchnerin am dritten Tage ein Quantum von etwa $50 \mathrm{~g}$ und mehr zu bilden. Glaubt man genügend für den Säugling erhalten zu haben, so nimmt man die Flasche, die sich noch immer fest ansaugt, ab, indem man den Warzenhof am Rande der Flasche etwas lüftet und die Flasche etwas nach unten senkt, sodaß Luft einströmen kann. Man hat nun die Frauenmilch in einer noch immer heißen Flasche. Es empfiehlt sich, die Flasche in Wasser von $37,5^{\circ} \mathrm{C}$ zu stellen, damit sie sich noch weiter abkühlt, was in 1-2 Minuten geschehen kann, und man kann sofort einen Saugpfropfen aufsetzen und dem Kind die Frauenmilch aus der Flasche geben resp, teelöffelweise einflößen. Beim Aussuchen der Flasche nimmt man in bezug auf die Weite des Halses Rücksicht auf die Brustwarze. So erhält man absolut steril und körperwarm Frauenmilch in genügender Quantität, ohne die Wöchnerin irgendwie zu quälen. Ja ich würde, wenn einmal die Mutter ihrem Kinde aus äußerlichen Gründen zu irgendeiner Tageszeit die Brust nicht geben kann, diese so gewonnene Muttermilch bei weitem einer Flasche Kuhmilch vorziehen, da sie auch viel steriler gewonnen ist als die Kuhmilch und die natürliche $\mathrm{Zu}$ sammensetzung hat. Vielleicht wird es möglich sein, manche Mutter zum Stillen zu bewegen, wenn man. ihr diese Erleichterung vor Augen hält. Manche oberflächlich beginnende Mastitis oder Milchstauung ist auf diese.die Biersche Saugmethode nachahmende Weise zu heilen.

\title{
Ein einfaches Verfahren zum Absaugen der Muttermilch.
}

Von San.-Rat Dr. Viktor Bock in Charlottenburg.

Das Stillgeschäft der Mutter scheitert sehr häufig daran, daß die Brustwarzen zu klein sind, um vom Säugling gefaßt zu werden, oder dieselben sind so empfindlich, daß die Mutter sich weigert zu stillen, oder sie sind wund, sodaß sie infolge Anlegens des Säug. lings nicht heilen können, oder der Säugling ist zu schwach, um Milch aus der Brust, besonders in den ersten Tagen nach der Geburt, saugen zu können. Um diesen Fatalitäten begegnen zu können, sind verschiedene Arten von Milchpumpen konstruiert worden, die alle auf dem Prinzip beruhen, da $B$ die Mutter selbst oder die Wärterin an einem Gummischlauch mit Mundstück saugen muß, wodurch die Milch in einen kleinen, flaschenförmigen Raum hineinfließt, oder man benutzt verschiedene Arten Gummihütchen, welche zum Schutz auf die wunde Brustwarze aufgesetzt und vom Săugling selber benutzt werden. Alle diese Gummiapparate, besonders aber die Milchpumpen, haben den Nachteil, daß jemand saugen $m u b$, was schwerer für einen Erwachsenen zu lernen ist als für einen Säugling, der es nicht zu lernen braucht, und außerordentlich anstrengend für die Mutter resp. Wärterin ist. Man kann daher manchmal sehen, wie sich abwechselnd sämtliche Familienmitglieder, den Arzt eingeschlossen, abmühen, der armen Wöchnerin die Milch abzuziehen; und welche Milch erhält man! Meist ist sie in der langen Zeit des Saugens kalt geworden, sie enthält gewiß auch manchen Keim aus dem Munde der Saugenden.

Um alle diese Unbequemlichkeiten zu vermeiden, habe ich ein einfaches Mittel kennen gelernt, das meines Wissens nicht allgemein bekannt ist. Man füllt eine gewöhnliche sogenannte Strichflasche, nachdem man sie natürlich vorher erwärmt hat, mit kochendem Wasser, läßt dieses einige Minuten darin, gießt es aus, wobei man natürlich die Flasche mit einem sauberen Tuch halten muß, da sie für die bloße Hand zu heiß ist, dann kühlt man schnell den Hals der Flasche mit einem sauberen, kühlen, leinenen Tuch (oder 